\title{
From bottom landers to observatory networks
}

\author{
Roland Person, Yannick Aoustin, Jerome Blandin, Jean Marvaldi and Jean-François Rolin \\ IFREMER, Centre de Brest, Plouzané, France
}

\begin{abstract}
For a long time, deep-sea investigation relied on autonomous bottom landers. Landers can vary in size from $200 \mathrm{~kg}$ weight to more than $2 \mathrm{t}$ for the heaviest scientific landers and are used during exploration cruises on medium periods, from one week to some months. Today, new requirements appear. Scientists want to understand in detail the phenomena outlined during exploration cruises, to elaborate a model for future forecasting. For this, it is necessary to deploy instrumentation at a precise location often for a long period. A new mode of ocean science investigation using longterm seafloor observatories to obtain four dimensional data sets has appeared. Although this concept has been proposed for many years, the high level of investment required limits the number of projects implemented. Only multidisciplinary programs, supported by a strong social requirement were funded. Some observatories have been deployed.
\end{abstract}

Key words landers - multidisciplinary long term observatories - global change - seismology - environment

\section{Introduction}

In this paper we recall how, during the last twenty years, deep-sea investigation moved from scarce observations in a unknown environment to continuous measurements of a wide set of parameters in carefully selected critical areas. In support of the analysis of this evolution, we will give a brief description of representative equipment or systems which were successively deployed during the period.

\section{Bottom landers}

Up to the 1980s deep-sea investigations relied on autonomous bottom landers while some sub-

Mailing address: Dr. Jean Marvaldi, IFREMER, Centre de Brest BP 70, 29280 Plouzané, France; e-mail: Jean.Marvaldi@ifremer.fr mersibles were used for visual observations only (e.g., Cyana). Landers, i.e. free falling shuttles launched from the sea surface and acoustically released after some time spent on the seafloor, could vary in size and weight from $100 \mathrm{~kg}$ to more than $2 \mathrm{t}$ for the heaviest scientific landers. Main problems encountered with landers are:

- The deployment period is limited to 1 to 3 months (because of power supply and data storage capacities).

- A lander can only support a small number of sensors.

- The free fall deployment of the instrument does not allow a precise location of the instrument to be choosen.

- There is no control of the instrument and in the early days it often failed at the beginning of the mission and no data were collected.

With the availability of deep-sea manned submersibles equipped with arms (e.g., Nautile, Alvin, Shinkai), low power electronic devices and improved batteries, a new generation of instruments appeared in the mid 80's. One example of this type of instrument was the three component ocean bottom microprocessor based seismometer developed by IFREMER from 1984 to 1986 in cooperation with the University 
of Brest and INSU (Institut National des Sciences de l'Univers) (Pascal et al., 1986).

A seismometer measures the motions of the ground in which it is embedded. A well designed instrument will detect them with a high accuracy and with low noise over a broad range of amplitudes and frequencies. The ground instrument coupling problem is crucial (Byrne et al., 1982; Guennou, 1988). This OBS (Ocean Bottom Seismometer) (fig. 1) was one of the first to separate geophones from the main pressure vessel and to place them at a one meter distance from the main frame on the seafloor. This design reduces the mechanical noise. The small geophone vessel can be optimised to have optimum horizontal and vertical coupling. The seismometer was also levelled to less than $2^{\circ}$ once laid on the seafloor. All

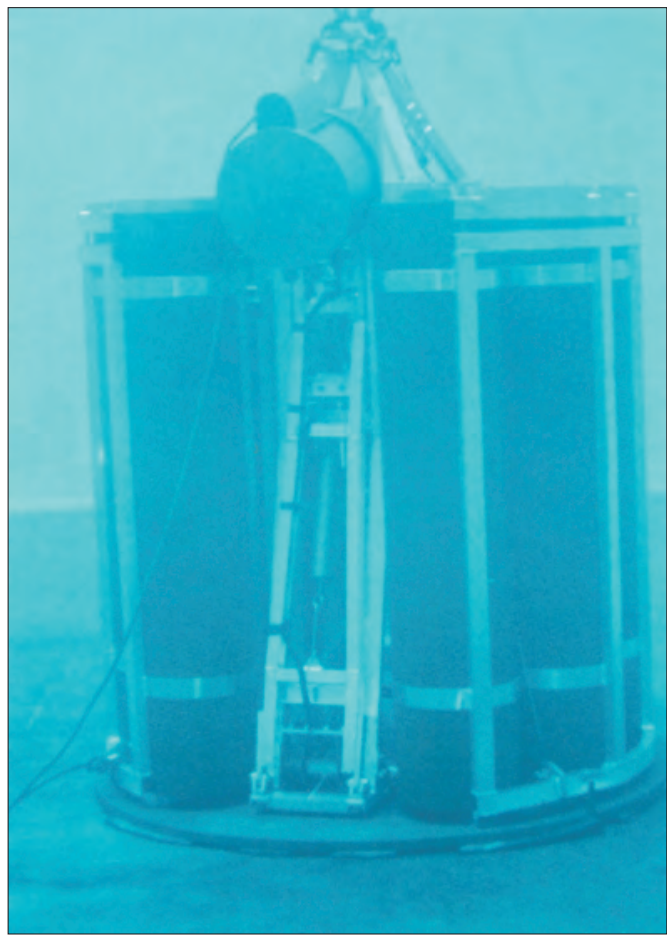

Fig. 1. The Pascal\&Person three components ocean bottom seismometer. The syntactic foam provides buoyancy. A lever arm deploys the cylindrical seismometer array from the main structure. broad band OBSs in use today are built on this concept. After the OBS had reached the seafloor, a rigid arm swang down with the sensor package when an explosive bolt was shot; then the pin holding the geophone package to the arm was pulled out by another explosive bolt. After dropping the package, the arm was automatically retracted firmly against the main structure by the pull of a stainless steel spring. Buoyancy was provided by syntactic foam cylindrical floats, allowing manipulation by the Nautile (glass spheres are forbidden for security reasons). The autonomy of the instrument rated for $6000 \mathrm{~m}$ operation, was more than 6 months and the functioning of the system was controlled acoustically throughout the deployment.

This prototype gave very good results during test deployments and scientific cruises on deep-sea sites off-shore Portugal and Crete.

At the same time many other European laboratories developed their own instruments in relation to their scientific interests, such as Bathysnap from SOC (Southampton Oceanographic Center) and landers from NIOZ (Netherlands Instituut voor Onderzoek der Zee) or GEOMAR. Bathysnap is a time lapse camera system operated in various forms by SOC (Lampitt and Burnham, 1983). It is a simple but effective example of an autonomous observatory system and made several important pioneering discoveries in the deep-sea environment.

\section{Landers and submersibles}

The ability to position a lander on a very well defined location with the Nautile led IFREMER to develop new instruments: OT 6000, NADIA2, SAMO.

\subsection{OT 6000: lander and submersible add their skills}

The OT6000 (Observatoire Thermique 6000 m) thermal observatory (fig. 2) was a self-contained instrument designed to measure temperature in the water layer in contact with the sea bottom and down to the depth of $60 \mathrm{~cm}$ in the sediment. It deploys five thermistor tempera- 


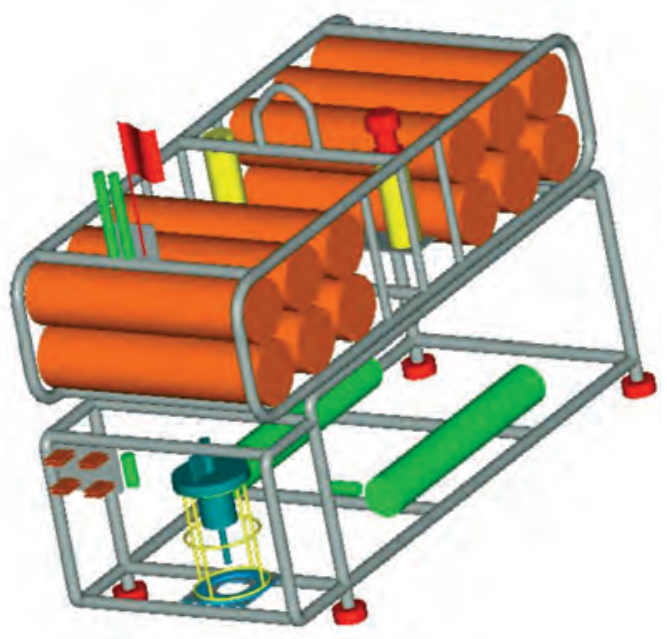

Fig. 2. The OT6000 thermal observatory is deployed and recovered as a lander (syntactic foam, acoustic release). The temperature needles are positioned by arms of the Nautile.

ture sensors, one in the sea bottom water layer approximately $2 \mathrm{~m}$ above the seafloor. The four sediment sensors are at the tip of thin steel rods vertically driven into the sediment upon deployment by the weight of a $50 \mathrm{~kg}$ cylindrical steel plate attached to their upper ends. The steel plate which is about $8 \mathrm{~cm}$ thick lies on the surface of the sediment after deployment. The rods are of different lengths, 30, 40 and $60 \mathrm{~cm}$ and provide temperature measurements at the corresponding penetration depths. The OT6000 thermal observatory was deployed at a selected site on the seafloor by the submersible Nautile.

The instrument was used during the KaikoNankai cruise (Japanese-French cooperation, August 1989) to estimate the total fluid flow out of the clam colonies in an area of approximately 500 by $625 \mathrm{~m}$ located on the first anticline landward of the frontal thrust at the toe of the Eastern Nankai accretionary complex.

\subsection{NADIA: the third dimension}

NADIA (Montagner et al., 1994) was a system which made it possible to re-enter an ODP hole and install different kinds of geophysical instrumentation in the borehole. This system was for example used during the OFM/SISMOBS experiment. NADIA (fig. 3) was an autonomous shuttle which was moved and controlled by the Nautile. It included the borehole device, a hydraulic winch, electric batteries and a hydraulic generator. An underwater mateable electric connector was used to connect the Nautile to NADIA. In a first phase, the shuttle is moved down to the ocean bottom. Then the Nautile dives and joins the shuttle. An auxiliary dead weight is released so that the weight of NADIA in water is about $20 \mathrm{~kg}$. Then the submersible moves the shuttle to the borehole and positions it. In a second phase the submersible is connected to NADIA using the mateable connector and the borehole device is deployed in

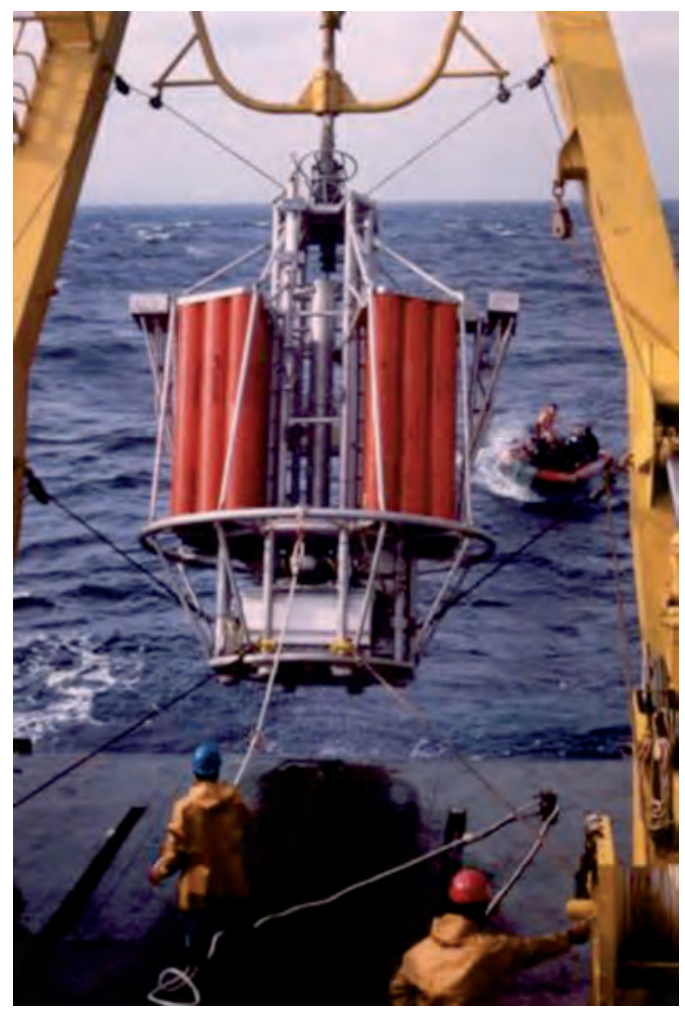

Fig. 3. NADIA being put in sea water. 
the borehole and the control is performed from the Nautile. Glass beads fill the portion of the hole containing the instruments to enhance the coupling with the surrounding rock medium while enabling the package to be extracted from the hole at the end of the experiment.

During the OFM/SISMOBS cruise a bottom package containing a set of CMG3 three component broadband seismometers was deployed during 10 days inside borehole 396B at a depth of $294 \mathrm{~m}$ below seafloor, at $4450 \mathrm{~m}$ water depth.

\subsection{SAMO: vision and near real time transmission}

SAMO (Station Abyssale de Mesures Océanographique) is a more complex instrument deployed by the Nautile or a ROV using a procedure similar to NADIA. It was designed to continuously monitor a hydrothermal vent. Colour pictures (fig. 4) are transmitted to the surface by an acoustic link upon acoustic command. Physical parameters (four temperatures and current) are continuously sampled and recorded. These data can also be transferred to the surface by acoustic command. Tests to transmit these pictures in real time from the seafloor of the rift in the Pacific Ocean to the Oceanographic Centre in Brest - France - took place in 1991, using INMARSAT satellite.

\subsection{HYDROGEO: long term $3 D$}

A further important step was a long-term observation in borehole. Back in the mid-80's, IFREMER started to monitor sediment temperature during one year deployments. The evolution of this equipment found an interesting challenge in 1994-1995: one and half years of monitoring of an Ocean Drilling Program Hole (no. 984D) after it was drilled in the Barbados Accretionary Prism. The hole was equipped with a sub seafloor monitoring instrumentation to determine the fluid pressure in the decollement and the thermal structure of the sediments after the drilling disturbances had dissipated. The Hole 984D was closed by a «CORK» (Cir-

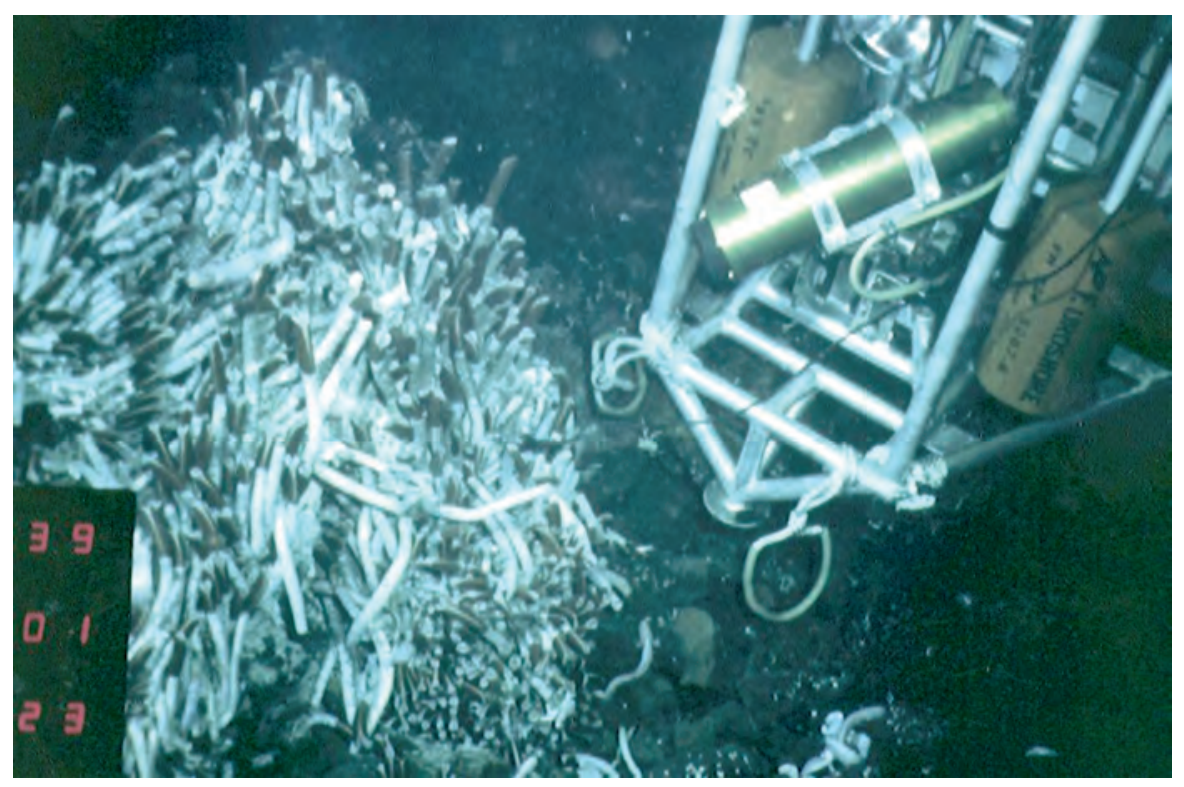

Fig. 4. SAMO is following up the hydrothermal biota with a video camera during some weeks. 
culation Obviation Retrofit Kit) system (Davis et al., 1992). A logger with an underwater pluggable connector and a sampling device were installed in the «CORK». A string of sensors was hanging under the «CORK», measuring both temperature and pressure down to $500 \mathrm{~m}$ below the seafloor (fig. 5). The technological choice was to have numerical sensors every $20 \mathrm{~m}$ (Foucher et al., 1997). A sigma-delta communication links them to the logger in the «CORK». The harsh sea water environment $\left(5\right.$ to $\left.40^{\circ} \mathrm{C}\right)$ was taken in account through a corrosion study and led to the choice of Hastelloy containers and glass epoxy composite bolts.

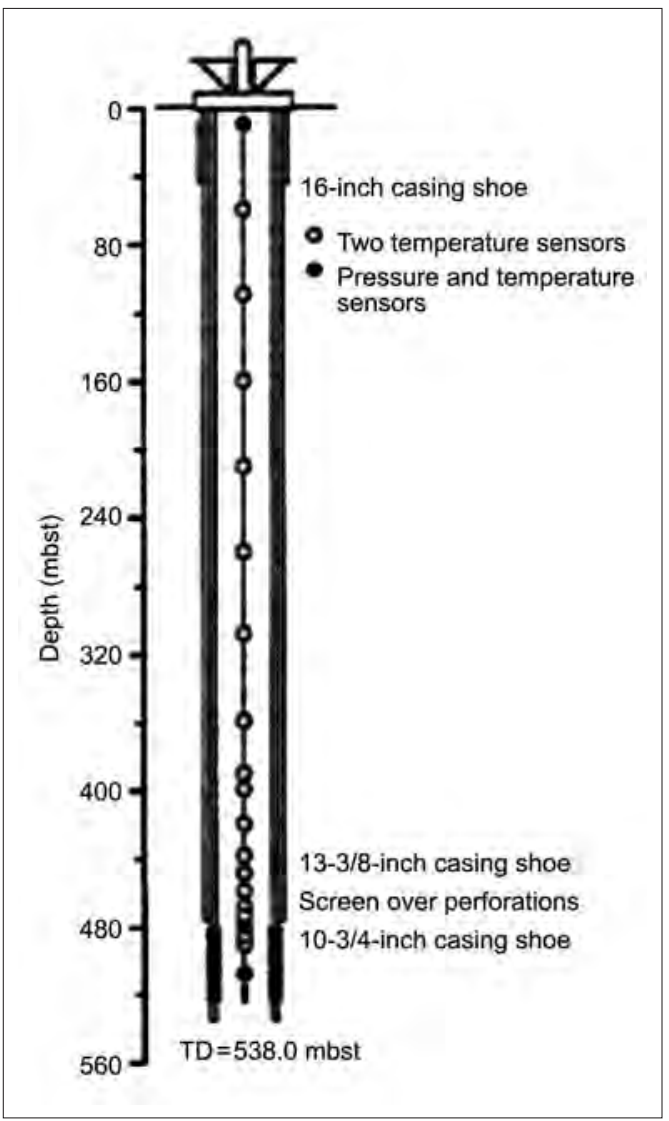

Fig. 5. Configuration of the sensor string under the CORK in the Hole 948D.
A testing methodology based on AFNOR standard NF X 10800 was established and applied. The reliability was demonstrated and the retrieval by submersible Nautile was successfully performed during the French-American cruise ODPNaut. The sensors were calibrated before and after deployment; the drifts were found lower than $0.1^{\circ} \mathrm{C}$ and $7 \cdot 10^{4} \mathrm{~Pa}$.

\subsection{New generation of European landers}

During this period similar developments were conducted by laboratories having access to submersibles (Alvin, Shinkhai, Mir, ...). Various scientific teams improved lander technology and developed more complex instruments. As an example we can cite DOBO, BOBO and University of Göteborg and IFM-GEOMAR landers.

\subsection{1. $\mathrm{DOBO}$}

DOBO lander (Bagley et al., 2004) is equipped with a time-lapse $35 \mathrm{~mm}$ reflex lens still camera (M8S, Ocean Instrumentation, U.K.) to monitor the response of deep-sea scavenging animals to bait (artificial food-falls). The camera is controlled by a custom built on-board control microprocessor. The camera can be biased to take photographs at times of interest if required by external control. The camera can take up to 1600 colour photographs on $35 \mathrm{~mm}$ Ektachrome colour reversal film (Kodak, U.K.) at a programmable interval greater than $30 \mathrm{~s}$. The camera is positioned at a $2 \mathrm{~m}$ height and at a fixed $82^{\circ}$ angle, photographing a $2.3 \times 1.6 \mathrm{~m}$ area of seafloor. To attract scavenging fauna in the field of view of the camera, bait is placed in the centre of the field of view.

\subsection{2. $\mathrm{BOBO}$}

The modular lander BOBO (van Weering et al., 1998) is designed for long (up to one year) in situ measurements in the lowermost 3 $\mathrm{m}$ of the benthic boundary layer, directly above the seabed, in water depths down to $5000 \mathrm{~m}$. The BOBO frame consists of three $2 \mathrm{~m}$ high 
legs. At the base of the legs, the BOBO has a width of $4 \mathrm{~m}$. The upper part of the BOBO lander consists of an hexagonal frame with a diameter of about $2 \mathrm{~m}$. The lander frame has been specially designed to remain on the seabed for periods of more than one year and the materials were selected in consequence. Exceptional care has been taken to avoid corrosion or electrolysis by isolating constitutive parts and connections. Additionally all instrumentation is mounted on Delrin blocks and instrument housings are either made of titanium or various kinds of plastics. Benthos glass spheres are attached to the upper part of the frame for buoyancy. The instrumentation is attached in the hexagonal frame and to the legs of the lander. Electrical power for the instruments is supplied by a battery pack that is housed in a glass sphere. Like any lander, BOBO is deployed by free fall from a surface vessel. Its descent speed is $57 \mathrm{~m} / \mathrm{min}$. Recovery is done by activating an acoustic release. Near-seabed current velocity and direction measurements are made by a customised $1200 \mathrm{kHz}$ high resolution broadband Acoustic Doppler Current Profiler (ADCP) made by RD Instruments. Salinity and temperature of the water are measured by a Sea-Bird SBE-16 conductivity/temperature recorder mounted at $2.5 \mathrm{~m}$ height in the frame. As an alternative the lander can be supplied with a Sea Tech transmissometer. For measurement of the amount, the temporal variability and the composition of near-seabed particle fluxes, a Technicap PS 4/3 sediment trap is fitted in the hexagonal frame. The BOBO lander can be equipped with other types of equipment as well.

\subsubsection{Göteborg lander-multisensor}

The research group led by Prof. Per Hall at Göteborg University (Sweden) has developed and operated autonomous landers (Karageorgis et al., 2003) since the early 1990s. Collaborative work between the group and research institutes in France, Denmark and the U.S.A. has resulted in the development and use of 5 different lander systems. Today two landers, one big and one small, are operated routinely in several European research projects. Both landers are built of non corrosive materials (Titanium and various plastics) as a modular system in which experimental modules can be exchanged as desired. The largest lander carries four experimental modules and has been successfully deployed about 80 times in water depths ranging from 20 to $5200 \mathrm{~m}$. The landers basically consist of two parts, an inner and an outer frame. The outer frame serves mainly as a carrier platform for the syntactic foam buoyancy package, the ballast and the acoustic system for the ballast release. The inner frame is a versatile system that carries the experimental module(s). These modules can easily be exchanged as desired. The module that has been in operation on the landers so far includes: chambers, or planar optode microelectrodes. The large Göteborg lander normally records data from up to 30 sensors including: turbidity and oxygen in the chambers and outside, salinity, depth and temperature sensors, current sensors (such as single point and profiling acoustic current meters) and a video camera.

\subsubsection{GEOMAR lander - The help of a launcher}

At present IFM-GEOMAR operates a suite of 8 landers of modular design as universal instrument carriers for investigations of the deepsea benthic boundary layer. 2 of these 8 landers have a squared design and carry a large benthic chamber covering $1 \mathrm{~m}^{2}$ sediment surface area to channel and measure fluid fluxes emanating from the seafloor (Vent Sampler System VESP). The second line, the «GEOMAR Lander System» (GML) is based on a tripod-shaped universal platform which can carry a wide range of scientific payloads to monitor, measure and perform experiments at the deepseafloor (Tengberg et al., 1995). Both types of landers can be either deployed in the conventional free-fall mode or targeted deployed on hybrid fibre optical or coaxial cables with a special launching device. The launcher enables accurate positioning on meter scale, soft deployment and rapid disconnection from the lander by an electric release. The bi-directional video and data telemetry provides online video transmission, power supply $(<1 \mathrm{~kW})$ and sur- 
face control of various relay functions. These landers provide a supporting platform system for:

- gas hydrate stability experiments;

- quantification of gas flow from acoustic bubble size imaging;

- integrated benthic boundary layer current measurements;

- quantification of particle flux;

- monitoring of mega-benthic activity;

- fluid and gas flow measurements at the sediment-water interface;

- biogeochemical fluxes at the sedimentwater interface (oxidants, nutrients).

Depending on the scientific mission and the material of the lander frame (stainless steel or titanium), the GML-System may carry a maximum payload of up to $450 \mathrm{~kg}$.

\section{Observatories}

\subsection{Concepts}

In the 1990s, in parallel to these efforts of landers, appeared the notion of benthic station and long term observatory. Scientists wanted to obtain four dimensional (space and time) data sets and long term observatories seemed to be the answer. On the impulse of the EC, discussions between European scientists tried to specify the technical needs and to conceive and evaluate the different solutions. A useful set of concepts and definitions was provided by Tecnomare SpA. Basic elements characterising a seafloor observatory are:

- multiple payload;

- autonomy;

- capability to communicate;

- possibility to be remotely reconfigured;

- positioning accuracy;

- data acquisition procedures compatible with those of on-shore observatories.

The necessity for multidisciplinary and crossdisciplinary investigations was emphasised. Three classes of observatories are currently identified:

Relocatable observatory - A system which is expected to be installed at a site for a limited period of time and capable of then being redeployed elsewhere. Although cable connectivity to shore may be attractive for some applications, most probably this class of observatories will be supported by mooring with satellite or radio communications to shore installations. A communication/power riser may be deployed from the seafloor to the surface or alternatively a vertical acoustic link is only used and the bottom equipment is self powered. The relocatable observatory may support an array of devices on the seafloor which are acoustically, electrically or fibre-optically linked, as well as AUVs and their docking stations.

Long-term observatory - An observatory which is expected to be installed at a site for decades or more. For some applications a mooring based installation may be convenient. But more often, this class of observatory will utilize an undersea cable from shore to provide power and communications. A long-term observatory will include a large number of nodes, each node supporting a range of devices.

Global/basin-scale observatory network An observatory designed to provide basin or global coverage through a network of observatories. Individual observatory nodes might be mooring or cable based.

At the present time many relocatable observatories have been developed and some longterm observatories are operational. Studies for global scale observatories were conducted, but there is as yet no network in operation.

\subsection{GEOSTAR}

European effort was focused on GEOSTAR (Beranzoli et al., 2000). More recently ASSEM and ORION projects allowed the concept of local network to be explored. These observatories in their present state belong to the class of relocatable observatories, but they may easily be transformed into long-term observatories. Landers will play a vital role in these developments. Targeted deployed landers with a wide range of instruments and sensors for physical, chemical, biogeochemical and biological parameters will be used in a single autonomous mode in relatively inaccessible areas (e.g., cold seep, hydrothermal vent and aphotic coral settings). They will also be used to test and qualify new 
sensors. Right now bi-directional communication with the lander is possible by using an acoustic link through a modem. In fact no technical frontier exists between landers and observatories but the main differences are relevant to data management and permanent long term deployment.

\subsection{Assem}

The ASSEM project (Blandin et al., 2003) consists in developing optimised means to measure and monitor a set of geotechnical, geodesic and chemical parameters distributed on a seabed area in order to better understand the slope instability phenomena and to assess and possibly anticipate the associated risks. The means are studied and realised to deploy a selection of adapted sensors on a seabed area (some $\mathrm{km}^{2}$ ) and transmit their data to shore for exploitation. A modular design as well as standard connecting and installation interfaces allow the system to be easily configured to the site of interest, to add new sensors, and to replace com- ponents for maintenance. An array is composed of several nodes. Each node (fig. 6) includes an electronic unit providing a set of enhanced sensors (pore pressure, methane, geodesy, tiltmeter, CTD, turbidity, currents, ...) with the means to communicate with the external world through an underwater acoustic or cabled network and to locally store the produced data. Alarms can also be generated by processing these data. The architecture is organised around an internal CAN/CAN open bus hosting sensors, communication and memory devices on a common transmission backbone. The software resources enabling a monitoring node to act as a network node (routing algorithms throughout the network, network configuration management, data transmission protocol and other network layers) are implemented in every electronic unit. Alarms can be generated for example if a critical parameter, or a group of parameters, comes above a programmed threshold for a given time. This distributed architecture allows a monitoring node to be easily configured and a new function added without modifying the existing functions. The same modularity concept is applied to

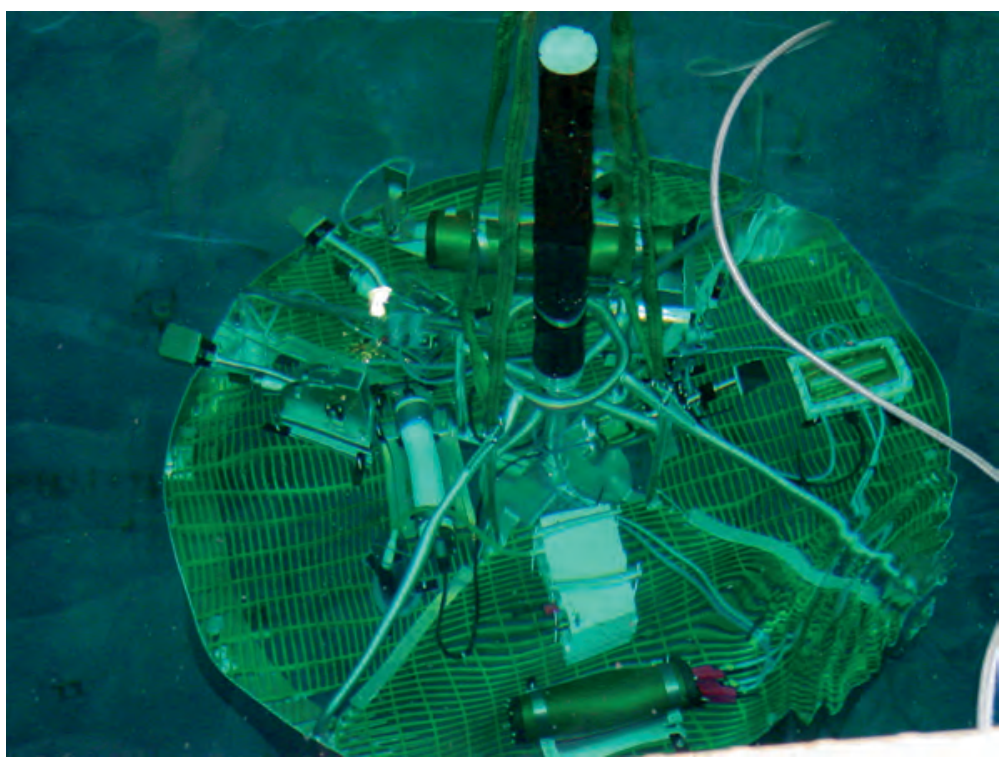

Fig. 6. ASSEM node. 


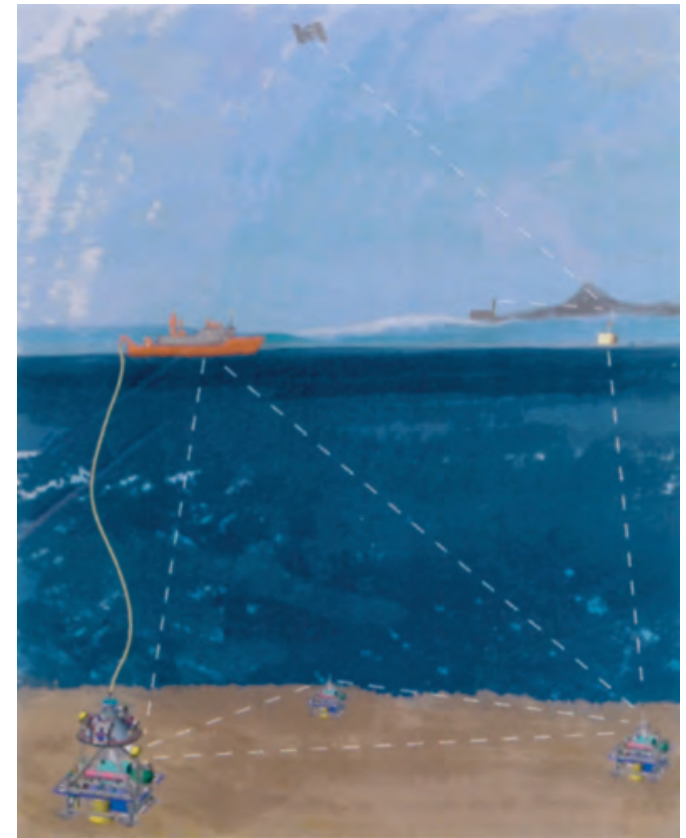

Fig. 7. ORION Observatory.

the mechanical design. Deployment and maintenance of the node imply a submersible or a ROV. Protection devices against trawling are used and the acoustic transmitter is installed on a special flexible arm.

Two complementary pilot experiments have been performed. The first took place at a site presenting a risk of slope instability in Norway. The second took place in the Gulf of Corinth. Compatibility between ASSEM and ORION communication systems (fig. 7) were demonstrated during this test.

\subsection{Outside Europe - U.S.A. and Japan}

In U.S.A., the HUGO (Hawaii Undersea Geo-Observatory), an automated submarine volcano observatory, was installed on the summit of the undersea Loihi seamount in October 1997 and connected to the shore via a $47 \mathrm{~km}$ long fibre optic cable. A failure appeared on 29th April 1998. No repair was possible. The instrumenta- tion included a seismometer, a hydrophone and a pressure sensor.

In September 1998, a permanent deep ocean scientific research facility - the Hawaii-2 Observatory or $\mathrm{H} 2 \mathrm{O}$ - was installed on a retired AT\&T submarine telephone cable that runs between Oahu, Hawaii and the California coast. The facility consists in a seafloor junction box and scientific sensors located at $5000 \mathrm{~m}$ water depth near $28^{\circ} \mathrm{N}$ latitude, $142^{\circ} \mathrm{W}$ longitude, that is to say about half way between Hawaii and California. The junction box draws $400 \mathrm{~W}$ of power from the cable to power both itself and user scientific instruments, and provides twoway communication through 8 digital ports with wet-mateable connectors. Instruments may be connected to the junction box using a ROV. Initial instrumentation at the $\mathrm{H} 2 \mathrm{O}$ site includes a broadband three-component seismometer, a short period geophone, a standard hydrophone and a pressure sensor. The $\mathrm{H} 2 \mathrm{O}$ system is connected to the Internet via the cable terminus on Oahu and the University of Hawaii. This offers marine scientists a new opportunity to deploy and operate instrumentation in the middle of the ocean. This long-term observatory in operation is the first seafloor node of the Global Seismographic Network.

In Japan, eight cabled observatory systems are in operation (Mikada, 2003). Hatsushima Island, in Sagami Bay, is the site of the first cabled observatory installed by the JAMSTEC (Japan's Marine Sciences and Technology Center) in 1993, at a depth of $1174 \mathrm{~m}$. This station consists of a CTD sensor, electromagnetic current meter, two video cameras, two ground thermometers, a seismometer and hydrophones. It is connected to the shore via a $8 \mathrm{~km}$ long fiber optic cable. Data are directly transmitted to the JAMSTEC Centre in Yokosuka. The area is a tectonically active region and a chemosynthetic community mainly composed of Calyptogena (giant white clams) thrives on methane and sulfides found in water seeping from underground. During the swarm of earthquakes in March 1997 scientists were able to videotape the mudflow believed to have occurred following a submarine landslide on the western slope of the station. Changes in ground temperature accompanied this event. It was the first long term mul- 
tidisciplinary observatory in operation in the world.

Two other JAMSTEC real-time cabled observatories are now also operating on the seafloor:

- off Muroto (120 km cable length);

- off Kushiro-Tokachi (240 km cable).

A first observatory was installed off Muroto in 1995. It was completed in 1997 by another station to form a local observation network. This one includes two real-time stations immersed at $1290 \mathrm{~m}$ and $3570 \mathrm{~m}$ depths, connected to the shore by a $120 \mathrm{~km}$ fibre optic cable and fitted with two seismometers and two quartz pressure sensors (tsunami detection), and some «mobile» observatories. These mobile observatories are not cabled. They consist in a central unit which includes several sensors (among which a seismometer and a pressure gauge) and 4 satellite units. A satellite unit consists in a three-component digital OBS with a storage capacity of 3 months. A synopsis of data collected in the central unit is transmitted to the shore every month via a messenger float sent to the surface to transmit data via ARGOS.

Five other real time observatories (see fig. 7 in Favali and Beranzoli, 2006) are deployed by JMA (Japan Meteorological Agency), ERI (Earthquake Research Institute) and NIED (Na-

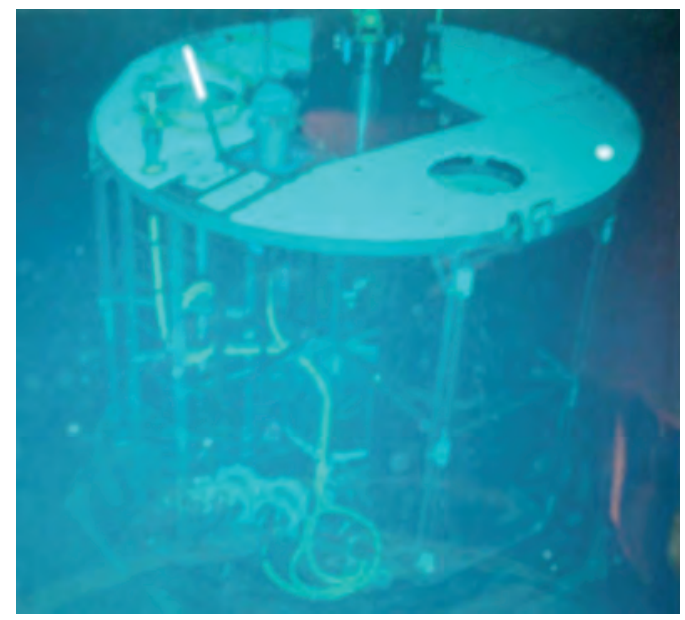

Fig. 8. Borehole observatory. tional research Institute for Earth science and Disaster prevention). Moreover, two borehole autonomous observatories (fig. 8) are implemented on ODP sites 1150 and $1151\left(39^{\circ} \mathrm{N}\right.$, $\left.143^{\circ} \mathrm{E}\right)$.

\section{Networked observatories (French Mediterranean Sea)}

Another specific observatory family is that of Neutrino detectors. One example is ANTARES (French Mediterranean Sea). All these observatories are only long-term observatories often multidisciplinary ones. But, despite the fact that sometimes several units are deployed in the same area, they do not yet constitute a network (different operators for example).

All the global/basin/plate-scale observatory networks are still at the state of proposals, with sometimes demonstration experiment.

\subsection{NEPTUNE}

The goal of the US-Canada NEPTUNE project (Delaney, 2003) is to establish a coherent system of submarine high speed communicationcontrol links using fibre-optic cables to connect remote interactive experimental sites with landbased research laboratories (see fig. 6 in Favali and Beranzoli, 2006). The system will provide real-time flux of data to shore, interactive control over robotic vehicles on site and power to the instruments and the vehicles. The whole Juan de Fuca plate will be investigated during 20 or 30 years under a multidisciplinary approach:

- subduction processes;

- plate interiors;

- spreading centers;

- sediment transport;

- upwelling and productivity;

- biological diversity;

- climate change.

Real-time two way communications at high rate (1-10 Gbps) are required to support large numbers of seafloor instruments and to anticipate changes in oceanographic technologies. Power between 50 and $100 \mathrm{~kW}$ can be derived from cables to instruments and robots. 


\section{2. $M A R S$}

The Monterey Accelerated Research System (MARS) cabled observatory will serve as the test bed for a state-of-the-art regional ocean observatory and represents the next step toward harnessing the promise of new power and communication technologies to provide a remote, continuous, long-term, high-power, large-bandwidth infrastructure for multidisciplinary, in situ exploration, observation, and experimentation in the deep-sea and an engineering test bed for NEPTUNE nodes. MARS (fig. 9) was installed in 2005 in Monterey Bay off-shore the Monterey Bay Aquarium Research Institute (MBARI). It includes one science node on $62 \mathrm{~km}$ of submarine cable with expansion capability for more nodes in the future (see fig. 6 in Favali and Beranzoli, 2006). The science node provides 4 science ports and each port has a 100 Mbit per second bi-directional telemetry channel. The node has the ability to deliver a total of $10 \mathrm{~kW}$ of power to the 4 ports.

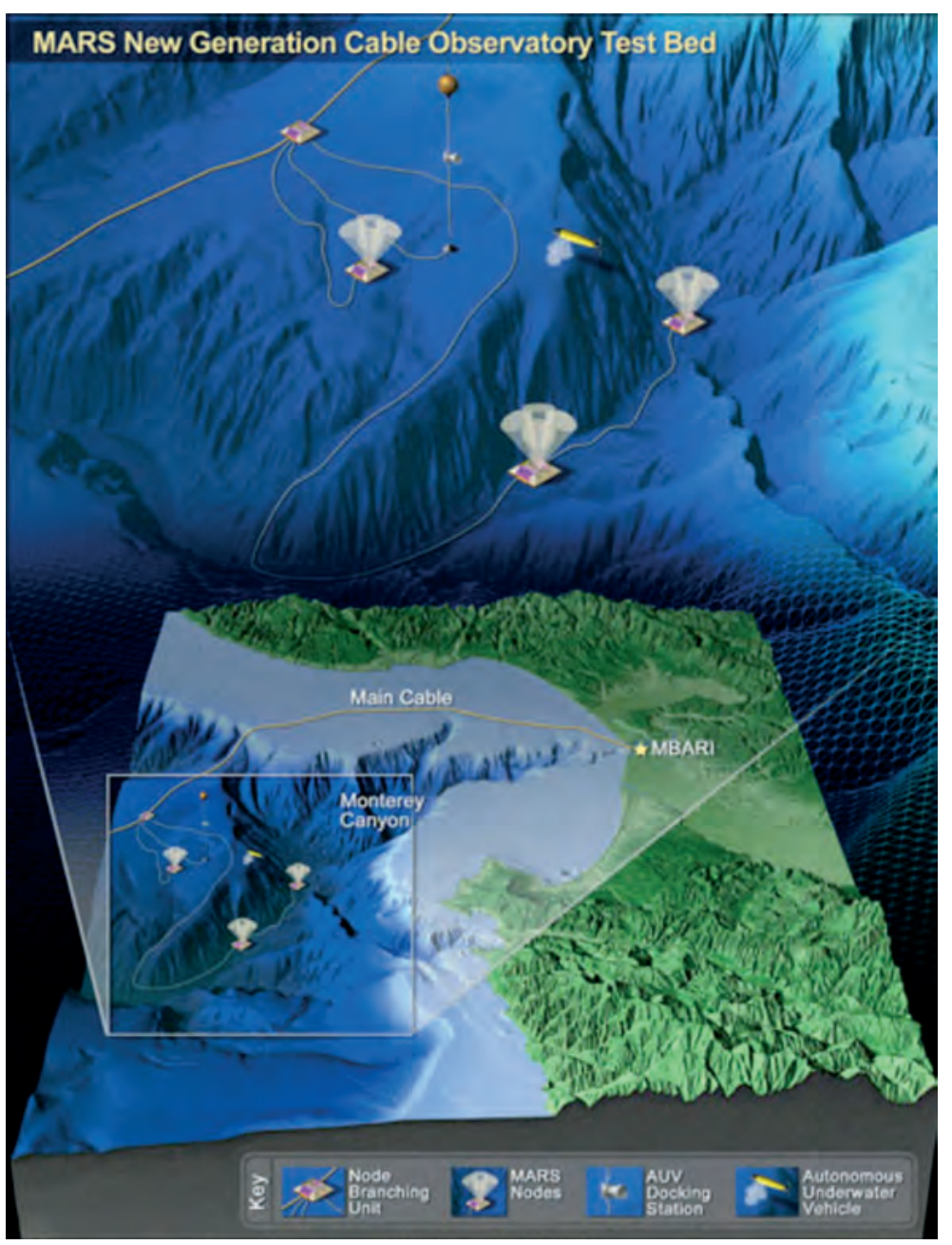

Fig. 9. MARS Observatory. 


\subsection{VENUS}

In Japan the VENUS project (see fig. 8 in Favali and Beranzoli, 2006) re-commissioned the second Trans-Pacific Ocean cable between Okinawa and Guam. The goal of VENUS is to construct a multidisciplinary Earth observation system. Technology for coaxial electric and fiber optic cables that permits them to be connected and disconnected underwater will be developed. A technique for connecting transfer units at the seafloor using submersible or ROV will also be developed. The Geo-TOC plans to install sensors in a relay unit.

\subsection{ESONET}

In Europe ESONET (Priede et al., 2002) proposes a network of seafloor observatories around the European Ocean Margin from the Arctic Ocean to the Black Sea for strategic long term monitoring as part of a GMES (Global Monitoring for Environment and Security) with capability in geophysics, geotechnics, chemistry, biochemistry, oceanography, biology and fisheries. Long-term data collection and alarm capability in the event of hazards (e.g., earthquakes) will be considered. ESONET will be developed from networks in key areas where there is industrial seafloor infrastructure, scientific/conservation significance (e.g., coral mounds) or sites suitable for technology trials (e.g., deep water close to land).

\section{Conclusions}

In less than thirty years observation of the ocean has moved from pseudo random sampling to well controlled measurements. Observatory networks will offer a new challenge by offering a complete set of continuous measurement and sampling at the same place. Communication support and deployment techniques are ready. Observatory networks will probably be deployed on a large scale (fig. 10) as soon as an extended set of reliable long term sensor packages is available.

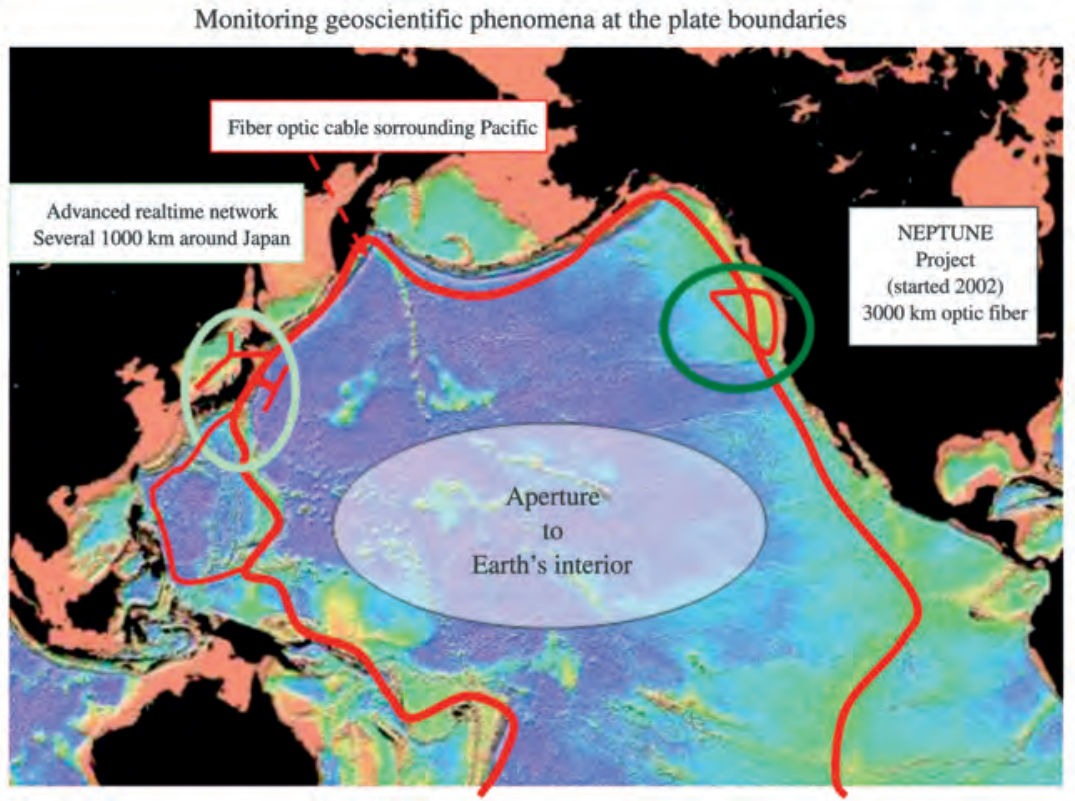

Fig. 10. Global scale observation network of Pacific Ocean. 


\section{REFERENCES}

Bagley, P.M., I.G. Priede, A.J. Jamieson, D.M. Bailey, E.G. Battle, C. Henriques and K.M. Kemp (2004): Lander techniques for deep ocean biological research, Underwater Technol., 26 (1), 3-12.

Beranzoli, L., T. Braun, M. Calcara, D. Calore, R. Campaci, J.-M. Coudeville, A. De Santis, G. Etiope, P. Favali, F. Frugoni, J.-L. Fuda, F. Gamberi, F. Gasparoni, H.W. Gerber, M. Marani, J. Marvaldi, C. Millot, P. Palangio, G. Romeo and G. Smriglio (2000): GEOSTAR the first European long term seafloor observatory, Eos, Trans. Am. Geophys. Un., 81 (5), 45-49.

Blandin, J., R. Person, J.M. Strout, P. Briole, G. Etiope, M. MAsson, S. Smolders, V. LyKousis and G. FerentiNOS (2003): ASSEM: a new concept of observatory applied to long term SEabed Monitoring of geohazards, in Proceedings of OCEAN'2003, San Diego, 349-355.

Byrne, D. A., G.H. Sutton, J. G. Blackington and F.K. DUENNEBIER (1983): Isolated sensor ocean bottom sesimometer, Mar. Geophys. Res., 5 (4), 437-449.

Davis, E.E., K. Becker, T. Petigrew, B. Carson and R. MACDonALD (1992): CORK: a hydrologic seal and downhole observatory for deep ocean boreholes, Proceedings of the Ocean Drilling Program, Init. Rep., 139 (College Station TX, Ocean Drilling Program), 45-53.

Delaney, J. (2003): NEPTUNE: Submarine networks of interactive laboratories at the scale of a tectonic plate; a new paradigm in the ocean and Earth sciences, in Proceedings of the Pacific Northwest Workshop, Portland State University.

FAVAli, P. and L. BERANZOLI (2006): Seafloor observatory science: a review, Ann. Geophysics, 49 (2/3), 515-567 (this volume).

Focher, J.P., P. Henry and F. HARMEGNIES (1997): Longterm Observations of Pressure and Temperature in Hole 948D, Barbados accretionary prism, Proceedings of the Ocean Drilling Program, Sci. Results, 156, 239245.

GunNou, C. (1988): Etude du couplage d'un sismographe grand fonf avec le sol, Thesis Ecole des Arts et Manufactures de Paris.

Karageorgis, A.P., H.G. Kaberi, A. Tengberg, V. ZerVAKIS, P.O.J. Hall and Ch.L. Anagnostou (2003): Comparison of particulate matter distribution, in rela- tion to hydrography, in the mesotrophic Skagerrak and the oligotrophic north-eastern Aegean Sea, Cont. Shelf Res., 23, 1787-1809.

LAMPITT, R.S. and M.P. BuRnham (1983): A free fall time lapse camera and current meter system «Bathysnap» with notes on the foraging behaviour of a bathyal decapod shrimp, Deep-Sea Res. I, 30, 1009-1017.

MikadA, H. (2003): Cabled Observatories in Japan-Technologies and Scientific Achievements (on line: http://neptunepower.apl.washington.edu/documentation/documentation.html).

Montagner, J.P., J.F. Karczewski, B. Romanowicz, S. Bouaricha, G. Roult, E. Stutzmann, J.C. Koenic and L. Floury (1994): The French pilot experiment OFM/SISMOBS: first scientific results on noise and event detection, Phys. Earth Planet. Int., 84, 321-326.

PAscal, G., R. Person and J.F. KARCZEWSKi (1986): A Three Components Ocean Bottom Microprocessor Based Seismometer (OI, Brighton).

Priede, I.G. and P.M. Bagley (2000): In situ studies on deep-sea demersal fishes using autonomous unmanned lander platforms, Oceanogr. Mar. Biol. Ann. Rev., 38, 357-392.

Priede, I.G., J. Mienert, R. Person, T.C.E.van Weering, O. Pfannkuche, N. O'NeIll, A. Tselepides, L. ThomSen, P. Favali, F. Gasparoni, N. Zitellini, C. Millot, H.W. Gerber and J.M.A. DE Miranda (2002): ESONET - European Seafloor Observatory NETwork, in Proceedings of the EuroGOOS 2002 Conference, 3-6 December, Athens (Greece), 291-294.

Tengberg, A., F. de Bovée, P. Hall, W. Berelson, B. Chadwick, G. Ciceri, P. Crassous, A. Devol, S. Emerson, J. Gage, R. Glud, F. Graziottin, J. Gundersen, D. Hammond, W. Helder, K. Hinga, O. HolBy, R. Jahnke, A. Khripounoff, H. Lieberman, V. Nuppenau, O. Pfannkuche, C. Reimers, G. Rowe, A. Sahami, F. Sayles, M. Schurter, D. Smallman, B. WEHRLI and P. DE WILDE (1995): Benthic chamber and profiling landers in oceanography - A review of design, technical solutions and functioning, Progr. Oceanogr., 35, 253-294.

van Weering, Tu.C.E., I.R. Hall, H.C. DE Stigter, I.N. MCCAVE and L. THOMSEN (1998): Recent sediments, sediment accumulation and carbon burial at Goban Spur, N.W., European Continental Margin $\left(47-50^{\circ} \mathrm{N}\right)$, Progr. Oceanogr., 42, 5-35. 